\title{
Editorial
}

\section{Empirical Finance}

\author{
Shigeyuki Hamori [ \\ Graduate School of Economics, Kobe University, 2-1, Rokkodai, Kobe 657-8501, Japan; hamori@econ.kobe-u.ac.jp
}

Received: 25 December 2019; Accepted: 26 December 2019; Published: 2 January 2020

\begin{abstract}
The research field related to finance has made great progress in recent years due to the development of information processing technology and the availability of large-scale data. This special issue is a collection of 16 articles on empirical finance and one book review. The content is six articles on machine learning, five articles based on traditional econometric analysis, and five articles on emerging markets. The large share of articles on the application of machine learning is in line with recent trends in finance research. This special issue provides a state-of-the-art overview of empirical finance from economic, financial, and technical points of view.
\end{abstract}

Keywords: machine learning; artificial intelligence; financial econometrics; emerging markets

Empirical research is crucial in finance. This research area has experienced remarkable progress due to the development of information technology. This Special Issue focuses on the broad topic of empirical finance and includes many studies using financial data. The Special Issue is mainly divided into three types of analysis: the application of machine learning based on artificial intelligence, the application of the traditional econometric approach, and the analysis of emerging markets.

The first group includes Wang et al. (2018); Liu et al. (2018); Vezeris et al. (2018); Xu et al. (2018); Ptak-Chmielewska (2019) and Hamori et al. (2018). Wang et al. (2018) proposed two estimation algorithms for extracting cross-lingual news pairs based on machine learning from multilingual financial news articles. Luo et al. (2019) introduced convolutional neural network (CNN) techniques to forecast the short-term crude oil futures prices. Vezeris et al. (2018) compared the addition of various strategies to a simple Moving Average Convergence Divergence (MACD) automated trading system. Xu et al. (2018) combined random forest and wavelet transformation to model the prediction of currency crises. Ptak-Chmielewska (2019) compared various machine learning methods to analyze small enterprise failures using individual-level data. Hamori et al. (2018) used default payment data to compare the prediction accuracy and classification ability of three ensemble learning methods and various neural network models.

The second group includes Ogawa and Muto (2019); Tivnan et al. (2018); Nakajima (2019); Miyazaki (2019) and Toyoshima (2018). To analyze the determinants of the utility of international currencies, Ogawa and Muto (2019) used a dynamic panel data model. Tivnan et al. (2018) used trading data and quote data to provide various measures of Securities Information Processor (SIP) latency related to high-speed data feeds between exchanges. Nakajima (2019) analyzed whether profit can be gained from statistical arbitrage between wholesale electricity futures and natural gas futures listed on the New York Commodity Exchange. Miyazaki (2019) analyzed how gold reacts to changes in various financial measures based on a quantile regression model. Toyoshima (2018) applied a two-step procedure to analyze the causality-in-mean and causality-in-variance between the housing and stock markets in the United Kingdom.

The third group includes Liu et al. (2018); He et al. (2018); Lizińska and Czapiewski (2019); Lu and Li (2019) and Thuy and Thuy (2019). Liu et al. (2018) used a copula model to study the dependence structure of the share price returns of Beijing Bank, Ningbo Bank, and Nanjing Bank in China. He et al. (2018) used a time-varying parameter vector autoregressive (VAR) model with 
stochastic volatility to analyze the dynamic relationship between Chinese house prices and bank credit. Lizińska and Czapiewski (2019) used a set of proxies of earnings management to test the long-term, Initial Public Offering (IPO) performance in Poland. Lu and Li (2019) applied panel data regression and piecewise regression models to analyze the institutional investor's shareholding base on the corporate governance system in Taiwan. To investigate the impact of exchange rate volatility on exports in Vietnam, Thuy and Thuy (2019) used the autoregressive distributed lag (ARDL) bounds testing approach.

Finally, Xu (2018) provided a book review on "Credit Default Swap Markets in the Global Economy" by Tamakoshi and Hamori. Routledge: Oxford, UK, 2018.

These articles all contribute to the development of empirical finance, addressing a wide range of issues and topics related to risk analysis, portfolio analysis, and risk attribution.

Funding: This work was supported by JSPS KAKENHI Grant Number 17 H00983.

Conflicts of Interest: The author declares no conflict of interest.

\section{References}

Hamori, Shigeyuki, Minami Kawai, Takahiro Kume, Yuji Murakami, and Chikara Watanabe. 2018. Ensemble Learning or Deep Learning? Application to Default Risk Analysis. Journal of Risk and Financial Management 11: 12. [CrossRef]

He, Xie, Xiao-Jing Cai, and Shigeyuki Hamori. 2018. Bank Credit and Housing Prices in China: Evidence from a TVP-VAR Model with Stochastic Volatility. Journal of Risk and Financial Management 11: 90. [CrossRef]

Liu, Guizhou, Xiao-Jing Cai, and Shigeyuki Hamori. 2018. Modeling the Dependence Structure of Share Prices among Three Chinese City Banks. Journal of Risk and Financial Management 11: 57. [CrossRef]

Lizińska, Joanna, and Leszek Czapiewski. 2019. Is Window-Dressing around Going Public Beneficial? Evidence from Poland. Journal of Risk and Financial Management 12: 18. [CrossRef]

Lu, Su-Lien, and Ying-Hui Li. 2019. Effect of Corporate Governance on Institutional Investors' Preferences: An Empirical Investigation in Taiwan. Journal of Risk and Financial Management 12: 32. [CrossRef]

Luo, Zhaojie, Xiaojing Cai, Katsuyuki Tanaka, Tetsuya Takiguchi, Takuji Kinkyo, and Shigeyuki Hamori. 2019. Can We Forecast Daily Oil Futures Prices? Experimental Evidence from Convolutional Neural Networks. Journal of Risk and Financial Management 12: 9. [CrossRef]

Miyazaki, Takashi. 2019. Clarifying the Response of Gold Return to Financial Indicators: An Empirical Comparative Analysis Using Ordinary Least Squares, Robust and Quantile Regressions. Journal of Risk and Financial Management 12: 33. [CrossRef]

Nakajima, Tadahiro. 2019. Expectations for Statistical Arbitrage in Energy Futures Markets. Journal of Risk and Financial Management 12: 14. [CrossRef]

Ogawa, Eiji, and Makoto Muto. 2019. What Determines Utility of International Currencies? Journal of Risk and Financial Management 12: 10. [CrossRef]

Ptak-Chmielewska, Aneta. 2019. Predicting Micro-Enterprise Failures Using Data Mining Techniques. Journal of Risk and Financial Management 12: 30. [CrossRef]

Thuy, Vinh, and Duong Thuy. 2019. The Impact of Exchange Rate Volatility on Exports in Vietnam: A Bounds Testing Approach. Journal of Risk and Financial Management 12: 6. [CrossRef]

Tivnan, Brian F., David Slater, James R. Thompson, Tobin A. Bergen-Hill, Carl D. Burke, Shaun M. Brady, Matthew T. K. Koehler, Matthew T. McMahon, Brendan F. Tivnan, and Jason G. Veneman. 2018. Price Discovery and the Accuracy of Consolidated Data Feeds in the U.S. Equity Markets. Journal of Risk and Financial Management 11: 73. [CrossRef]

Toyoshima, Yuki. 2018. Testing for Causality-In-Mean and Variance between the UK Housing and Stock Markets. Journal of Risk and Financial Management 11: 21. [CrossRef]

Vezeris, Dimitrios, Themistoklis Kyrgos, and Christos Schinas. 2018. Take Profit and Stop Loss Trading Strategies Comparison in Combination with an MACD Trading System. Journal of Risk and Financial Management 11: 56. [CrossRef] 
Wang, Zhouhao, Enda Liu, Hiroki Sakaji, Tomoki Ito, Kiyoshi Izumi, Kota Tsubouchi, and Tatsuo Yamashita. 2018. Estimation of Cross-Lingual News Similarities Using Text-Mining Methods. Journal of Risk and Financial Management 11: 8. [CrossRef]

Xu, Haifeng. 2018. Book Review for "Credit Default Swap Markets in the Global Economy" by Go Tamakoshi and Shigeyuki Hamori. Oxford: Routledge, ISBN 978113824472.

Xu, Lei, Takuji Kinkyo, and Shigeyuki Hamori. 2018. Predicting Currency Crises: A Novel Approach Combining Random Forests and Wavelet Transform. Journal of Risk and Financial Management 11: 86. [CrossRef]

(c) (2)

(C) 2020 by the author. Licensee MDPI, Basel, Switzerland. This article is an open access article distributed under the terms and conditions of the Creative Commons Attribution (CC BY) license (http://creativecommons.org/licenses/by/4.0/). 